\title{
Association Between Emphysema Score, Six-Minute Walk and Cardiopulmonary Exercise Tests in COPD
}

\author{
Li-Fei Chen ${ }^{\S}$, Chun-Hua Wang ${ }^{*} \S$, Pai-Chien Chou, Shu-Chuan Ho, \\ Wen-Ching Joa, Te-Fang Sheng and Han-Pin Kuo
}

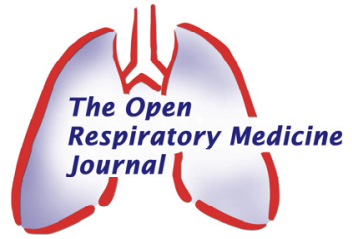

Pulmonary Medicine Research Center, Department of Thoracic Medicine, Chang Gung Memorial Hospital, Taipei, Taiwan, 199 Tun-Hwa North Road, Taipei, Taiwan

\begin{abstract}
Background: High-resolution computed tomography (HRCT) has allowed in detection of airway wall abnormalities and emphysema, whose extent may correlate with the clinical severity of the disease in patients with chronic obstructive pulmonary disease (COPD). Six minute walk test (6MWT) and cardiopulmonary exercise test (CPET) can determine functional status.

Methods: A study was undertaken to investigate whether the extent of emphysema in COPD patients quantitatively confirmed by HRCT scoring was associated with distance walked, inspiratory capacity (IC) changes after exercise, anaerobic threshold of cardiopulmonary exercise and the BODE index (body mass index, airflow obstruction, dyspnea, exercise performance).

Results: Seventeen patients with COPD underwent HRCT scanning, 6MWT and CPET. The emphysema score was highly correlated to forced vital capacity (FVC) $(\mathrm{r}=-0.748, \mathrm{p}<0.001)$, forced expiratory volume in 1 second $(\mathrm{FEV} 1)(\mathrm{r}=-0.615$, $\mathrm{p}<0.01)$, IC post exercise $(\mathrm{r}=-0.663, \mathrm{p}<0.01)$ and dyspnea score post exercise $(\mathrm{r}=0.609, \mathrm{p}<0.01)$, but was not associated with the BODE index. The distance walked during $6 \mathrm{MWT}$ was inversely correlated to emphysema score $(\mathrm{r}=-0.557$, $\mathrm{p}<0.05$ ). IC before exercise was highly related to the 6MWT. The change in IC after exercise was associated with the percent decline of oxygen saturation after exercise $(r=0.633, p<0.01)$. Severity of lung emphysema in COPD patients was inversely correlated to $\mathrm{VO}_{2} \max (\mathrm{r}=-0.514, \mathrm{p}<0.05)$ and anaerobic threshold $(\mathrm{r}=-0.595, \mathrm{p}<0.01)$ of cardiopulmonary exercise.

Conclusions:These results suggest that COPD associated with emphysema on HRCT is characterized by more severe lung function impairment, greater exercise impairment and cardiopulmonary dysfunction.
\end{abstract}

Keywords: Chronic obstructive pulmonary disease, High-resolution computed tomography, Six-minute walk test, cardiopulmonary exercise test, Inspiratory capacity.

\section{INTRODUCTION}

Chronic obstructive pulmonary disease (COPD), characterized by airflow limitation associated with partial reversible to bronchodilators [1], is a growing global epidemic problem [2]. Pulmonary function tests offer a convenient tool for earlier screening of disease, and assessing the progression of lung disease [3]. Several anatomic lesions of COPD, including peribronchiolar fibrosis and pulmonary emphysema, may contribute to fixed airflow limitation [4]. Due to its heterogeneous etiology [5], various tests has been developed to identify patients with high risk for early disease progression. Currently, quantitative analysis of high resolution commuted

*Address correspondence to this author at the 199 Tun-Hwa North Road,
Taipei, Taiwan. Pulmonary Medicine Research Center, Department of
Thoracic Medicine, Chang Gung Memorial Hospital, Taiwan; Tel: 8863
3281200, Ext. 8470; Fax: 8863 3272474; E-mail: wchunhua@ms7.hinet.net

${ }^{\#}$ Kuo, H-P. contributed equally as the co-corresponding author.

${ }^{\S}$ Chen, L-F and Wang, C-H contributed equally to this project as co-first author. tomography (HRCT) scans provides an objective measure of the extent and/or severity of emphysema [6,7]. The extent of involvement on CT study correlates with the lung function [8, 9]. Visual assessment of HRCT scans via Visual HRCT-score could be used as the noninvasive "gold standard" to assess severity and extent of emphysematous destruction [10].

In COPD, pulmonary function impairment is associated with multiple manifestations of functional limitation among patients [3]. Assessment of exercise capacity allows one to determine the severity of disease and its changes with time or treatment $[11,12]$ and is important in the management of patients with COPD. Both Peak Oxygen Uptake (peak $\mathrm{VO}_{2}$ ), from cardiopulmonary exercise testing (CPET) and the distance walked during a six-minute walk test (6 MWT) are used for following the natural history of various diseases, and for assessing the response to therapeutic interventions [13]. 6MWT, a submaximal exercise test, represent a useful marker for exercise capacity and dynamic hyperinflation of COPD patients $[14,15]$. CPET, while highly related to maximal oxygen consumption $\left(\mathrm{VO}_{2} \mathrm{max}\right)$, is used for evaluation of the severity of the disease and the degree of disability of COPD patients [16, 17]. 
However, it is still unclear whether there are direct links between exercise capacity and anatomical changes in patients with COPD. We therefore performed a prospective study to examine the relationships between the extent of emphysema (as measured by HRCT), airflow obstruction (as measured on spirometry) and exercise capacity (as measured by 6 minute walk test and CPET) in COPD patients. We hypothesized that a greater extent of HRCT-defined emphysema and more severe airflow obstruction would be associated with walking distance, changes in inspiratory capacity (IC) after exercise, and anaerobic threshold of cardiopulmonary exercise. We also hypothesized that these relationships would be linear across a spectrum from normal lung structure and function to severe emphysema and airflow obstruction.

\section{MATERIALS AND METHODS}

\section{Subjects}

Seventeen patients with COPD were recruited from July 2008 to July 2010 and were selected on the following criteria: age 60 to 80 years, non-smoker or cigarette smoking 10 pack years, absence of any pathology possibly interfering with the ability to perform exercises, and willingness to undergo study-related testing that included spirometry, HRCT scan of the chest, and respiratory questionnaire. Seventeen patients (aged 73.5 \pm 5.7 years; BMI: $22.3 \pm 3.5$ $\mathrm{Kg} / \mathrm{m}^{2}$ ) diagnosed to be COPD according to Global Initiative for Chronic Obstructive Lung Disease criteria [1] were included in this study. These patients were clinically stable without baseline oxygen desaturation, increased wheezing, cough, dyspnea or sputum over the previous 3 months. The project was approved by the Human Research Ethics Committees of Chang Gung Memorial Hospital. Informed consent was obtained from all subjects.

\section{Six Minute Walk Test (6MWT)}

Patients were instructed to walk back and forth at their own pace in a $35 \mathrm{~m}$ corridor. A physiotherapist supervised the test through the course, telling the patient the remaining exercise time every $2 \mathrm{~min}$. Dyspnea during the test was evaluated with the modified Borg dyspnea score. Pulmonary function test, inspiratory capacity, and dyspnea score, together with the walking distance were recorded before and after walking. Heart rate and oxygen saturation were monitored during the whole procedure.

\section{Cardiopulmonary Exercise Test (CPET)}

Each patient underwent a physician-supervised standard incremental cycle ergometer CPET until the symptomlimited maximum. Work rate were increased by 5 or $10 \mathrm{~W}$ per min after initially $1 \mathrm{~min}$ pedalling at $0 \mathrm{~W}$ for approximately $10 \mathrm{~min}$. Measurements as breath-by-breath ventilation, $\mathrm{O}_{2}$ and $\mathrm{CO}_{2}$ concentrations, derived minute ventilation, $\mathrm{VO}_{2}$ and $\mathrm{VCO}_{2}$ were determined by the Cardiopulmonary Exercise System "CPX/D". The oxygen pulse was calculated by dividing $\mathrm{VO}_{2}$ by heart rate. Anaerobic threshold was detected using the V-slope method using computerized regression analysis of the slopes of the $\mathrm{CO}_{2}$ uptake $\left(\mathrm{VCO}_{2}\right)$ vs $\mathrm{O}_{2}$ uptake $\left(\mathrm{VO}_{2}\right)$ plot, which detects the beginning of the excess $\mathrm{CO}_{2}$ output generated from the buffering of $\left[\mathrm{H}^{+}\right]$. Maximum voluntary ventilation (MVV) was estimated from the forced expiratory volume in $1 \mathrm{~s}$ $\left(\mathrm{FEV}_{1}\right)$ by the equation: $\mathrm{FEV}_{1} \times 40 \mathrm{~L} / \mathrm{min}$.

\section{Score of High Resolution Computed Tomography (HRCT)}

Visual assessment of HRCT scans has been widely used as the noninvasive "gold standard" in the calculation of sensitivity and specificity of routine lung function parameters and assessment of the severity and extent of emphysematous destruction [10]. The majority of studies have shown reasonably good correlations between CT emphysema scores and pathological specimen, a good agreement between expert readers for the assessment of the presence and extent of emphysema, and good correlations between subjective and objective assessment of emphysema $[10,18,19]$. Pulmonary emphysema was visually assessed by an expert chest radiologist unaware of the clinical and lung function data. The quantitative evaluation of emphysema was obtained by visual score technique according to Sakai and colleagues [20].

CT scans were performed on a GE SYTEC 3000 scanner (3 s, $160 \mathrm{mAs}$, and $120 \mathrm{kVp}$ ) without infusion of contrast medium. The patients held breath at full inspiration by using 1-mmcollimation (HRCT) scan. Hardcopy images were photographed using window settings appropriate for the lungs (level: -500 to $-700 \mathrm{HU}$; width: 1,000 to 1,500 HU). On three HRCT slices (at the level of the carina, $5 \mathrm{~cm}$ above and $5 \mathrm{~cm}$ below carina) the lung parenchyma was assessed for two aspects of emphysema: severity and extent [10, 20]. The three levels were graded and scored separately for the left and right lung, giving a total of six lung fields. Severity was graded on a 4-point scale: 0, no emphysema; 1, low HRCT attenuation areas $<5 \mathrm{~mm}$ in diameter with or without vascular pruning; 2, circumscribed low HRCT attenuation areas $>5 \mathrm{~mm}$ in diameter in addition to those $<5 \mathrm{~mm}$ in diameter (vascular pruning is present, but with normal lung intervening); 3, diffuse low attenuation areas without intervening normal lung or confluent larger low attenuation areas with vascular pruning and distortion of the branching pattern of the lung, occupying all or almost all of the involved parenchyma. The extent of emphysema using the direct observation method was on a 4-point scale. The same six lung fields were used and the extent score was $1,25 \%$ of the lung field involved; 2, 25 to $50 \%$ involvement; 3,50 to $75 \%$ involvement; 4,75 to $100 \%$ involvement. The final emphysema score of each lung field= severity times extent. The sum of total score in both lung field is from 0 to 72 .

\section{Statistics}

Data are presented as means \pm SD. The SPSS 14.0 software package was used for statistical analyses, and a value of $\mathrm{p}<0.05$ was considered significant. Pearson correlation analyses were used to determine the correlations between HRCT emphysema score, 6MWT and CPET data.

\section{RESULTS}

\section{Subject Characteristics}

17 COPD male patients among different GOLD stage (IIV) were recruited in this study. Baseline smoking status, lung function tests, BMI, 6MW test and CPET test measurements are listed in Table $\mathbf{1 .}$ 
Table 1. Characteristics of COPD Patients

\begin{tabular}{|c|c|}
\hline Sex, M/F & $17 / 0$ \\
\hline Age, yr & $73.5 \pm 5.7(61-79)$ \\
\hline BMI & $22.3 \pm .5(16.8-30.5)$ \\
\hline Smoker/ever-smoker/Nonsmoker & $5 / 12 / 0$ \\
\hline GOLD Stage (I/II/III/IV) & $1 / 6 / 6 / 4$ \\
\hline $\mathrm{FVC}, \mathrm{L}$ & $1.7 \pm 0.1$ \\
\hline FVC, $\%$ predicted & $54.5 \pm 13.2$ \\
\hline FEV1, L & $0.9 \pm 0.1$ \\
\hline FEV1, \% predicted & $43.1 \pm 16.2$ \\
\hline FEV1/FVC & $52.6 \pm 9.9$ \\
\hline BODE Index & $4.1 \pm 1.6(0-7)$ \\
\hline \multicolumn{2}{|l|}{$6 \mathrm{MWT}$} \\
\hline Distance, $\mathrm{m}$ & $380.6 \pm 51.9(272-468)$ \\
\hline Baseline dyspnea Borg score & $1(0-3)$ \\
\hline Post-exercise Dyspnea Borg Score & $4.9(3-8)$ \\
\hline Baseline IC, L & $1.15 \pm 0.37$ \\
\hline Post-exercise IC, L & $1.16 \pm 0.35$ \\
\hline $\mathrm{SaO}_{2}$ & $95.4 \pm 1.6$ \\
\hline HRCT Emphysema Score & $17.1 \pm 14.9(2-51)$ \\
\hline $0-10$ & 8 \\
\hline $11-20$ & 4 \\
\hline $21-30$ & 3 \\
\hline$>30$ & 2 \\
\hline \multicolumn{2}{|l|}{ CPET } \\
\hline AT (Aerobic Threshold), $\mathrm{ml} / \mathrm{kg} / \mathrm{min}$ & $4.6 \pm 1.9$ \\
\hline $\mathrm{AT} \mathrm{VO}_{2}, \mathrm{ml} / \mathrm{min}$ & $621.1 \pm 120.0$ \\
\hline $\mathrm{AT} \mathrm{VCO}_{2}, \mathrm{ml} / \mathrm{min}$ & $595.1 \pm 110.0$ \\
\hline $\mathrm{VO}_{2} \max , \mathrm{ml} / \min$ & $757.1 \pm 168.8$ \\
\hline
\end{tabular}

Abbreviations: GOLD: Global initiative for lung disease; FVC: forced vital capacity; FEV1: Forced expiratory volume in $1 \mathrm{sec}$; $\mathrm{L}$ : liter; $\mathrm{SaO}_{2}$ : Saturation of oxygen; BODE: the body-mass index (B), the degree of airflow obstruction $(\mathrm{O})$ and functional dyspnea (D), and exercise capacity (E).

\section{HRCT Emphysema Score}

HRCT was performed for all patients. Emphysema scores were calculated from HRCT to assess individual's emphysema severity and extent. Patient's emphysema score was measured and summarized as Table $\mathbf{2}$.

\section{Correlation Between HRCT Emphysema Score and 6MWT}

To investigate the correlations between lung function with emphysema burden, lung function measurements include FVC, \% predicted value of FVC, FEV1, \% predicted value of FEV1, Inspiratory capacity, ERV/IC, $\mathrm{O}_{2}$ saturation, Borg Scale, are recorded both pre- and post- exercise during the 6 minute walk test (Table 2). FVC (pre- and postexercise), $\%$ predicted value of FVC (pre- and post- exercise), FEV1 (pre- and post- exercise), \% predicted value of FEV1 (pre- and post- exercise), IC (pre- and postexercise), and post-exercise oxygen saturation were negatively associated with emphysema score (Table 2). ERV/IC (pre- and post-exercise), and post-exercise Borg scale were positively correlated with the emphysema score (Table 3). The walking distance in 6MWT was negatively associated with HRCT emphysema score (Fig. 1A), positively correlated with pre-exercise IC (Fig. 1B), and positively related to \% predicted value of pre-exercise FEV1 (Fig. 1C). It means that walking performance is related to anatomical and airflow limitation. The change in IC after exercise directly correlates with post-exercise desaturation (Fig. 2), which also correlates with HRCT emphysema score (Table 3).

\section{Correlations Between HRCT Emphysema Score and CPET}

CPET was performed in all patients. The patients' parameters are presented in Table 4. HRCT emphysema score was correlated with CPET measurements. The results demonstrated that FVC (Pre- and Post- exercise), \% predicted value of FVC (pre- and post- exercise), FEV1 (Preand Post-exercise), \% predicted value of FEV1 (pre- and post- exercise), IC (Pre- and Post-exercise), AT and $\mathrm{VO}_{2}$ max are inversely correlated with emphysema score and \% positively correlated to $\%$ predicted value of FEV1 before exercise (Fig. 3); while pre-exercise HR and Borg scale are positively associated with the score (Table 5).

\section{DISCUSSION}

We investigated whether the extent of emphysema in COPD patients quantitatively confirmed by HRCT scoring was associated with distance walked, change in inspiratory capacity (IC) after exercise measured by 6MWT, and anaerobic threshold measured by CPET. Patients with different severities of COPD based on GOLD criteria were included. The lung emphysema score were measured by HRCT. There were correlations between FVC, FEV1, IC, and post-exercise oxygen saturation both in the 6MWT and CPET study. This study has clarified which measures of pulmonary function from 6MWT and CPET can be used to assess the extent of emphysema, and which ones correlate best with HRCT scan results.

COPD is a disease associated with several systemic manifestations [21], resulting in impaired functional capacity, worsening dyspnea, and increased mortality [22]. Pulmonary rehabilitation remains the gold treatment for COPD patients and results in improved exercise tolerance and well-being [23]. To access the functional exercise tolerance and effects of pulmonary rehabilitation program, $6 \mathrm{MWT}$ can be used as follow up in terms of the changes of walking distance [24]. The walking distance in 6MWT was negatively associated with HRCT emphysema score (Fig. 1A), positively correlated with pre-exercise IC and \% predicted value of FEV1 (Fig. 1B, C). This implies that the anatomical limitation of lung structure which results in dynamic collapse and ventilation/perfusion problem may affect the general walking performance. Analysis of factors related to inspiratory capacity, we demonstrated that change in IC after exercise directly correlates with post-exercise 
Table 2. HRCT Emphysema Scores and 6 Minute Walk Test

\begin{tabular}{|c|c|c|c|c|c|c|c|c|c|c|c|c|c|c|c|}
\hline \multirow[b]{2}{*}{ Patient } & \multirow[b]{2}{*}{ Stage } & \multirow{2}{*}{$\begin{array}{c}\text { HRCT } \\
\begin{array}{c}\text { Emphysema } \\
\text { Score }\end{array}\end{array}$} & \multirow[b]{2}{*}{$\begin{array}{l}\text { Distance, } \\
\mathbf{m}\end{array}$} & \multirow[b]{2}{*}{$\begin{array}{c}\text { Pre- } \\
\text { FVC } \\
\text { L }\end{array}$} & \multirow[b]{2}{*}{$\begin{array}{c}\text { Post- } \\
\text { FVC } \\
\text { L }\end{array}$} & \multirow[b]{2}{*}{$\begin{array}{c}\text { Pre- } \\
\text { FEV1 } \\
\text { L }\end{array}$} & \multicolumn{9}{|c|}{ 6MWT } \\
\hline & & & & & & & $\begin{array}{c}\text { Post- } \\
\text { FEV1 } \\
\text { L }\end{array}$ & $\begin{array}{l}\text { Pre- } \\
\text { Borg } \\
\text { Scale }\end{array}$ & $\begin{array}{l}\text { Post- } \\
\text { Borg } \\
\text { Scale }\end{array}$ & $\begin{array}{c}\text { Pre- } \\
\text { IC, } \\
\text { L }\end{array}$ & $\begin{array}{c}\text { Post- } \\
\text { IC, } \\
\text { L }\end{array}$ & $\begin{array}{l}\text { Delta- } \\
\text { IC }\end{array}$ & $\begin{array}{c}\text { Pre- } \\
\mathrm{SaO}_{2} \text {, } \\
\%\end{array}$ & $\begin{array}{c}\text { Post- } \\
\mathrm{SaO}_{2}, \\
\%\end{array}$ & $\begin{array}{c}\text { BOD } \\
\text { E } \\
\text { Index }\end{array}$ \\
\hline 1 & IV & 14 & 424 & 1.78 & 1.65 & 0.53 & 0.61 & 2 & 5 & 1.61 & 1.14 & -0.47 & 94 & 82 & 6 \\
\hline 2 & IV & 51 & 272 & 0.98 & 0.90 & 0.64 & 0.56 & 0 & 8 & 0.86 & 0.82 & -0.04 & 94 & 82 & 3 \\
\hline 3 & III & 18 & 396 & 1.61 & 1.81 & 0.74 & 0.84 & 0 & 4 & 0.86 & 1.01 & 0.15 & 96 & 91 & 5 \\
\hline 4 & II & 4 & 384 & 1.78 & 1.74 & 1.00 & 1.03 & 2 & 7 & 0.91 & 0.92 & 0.01 & 97 & 87 & 5 \\
\hline 5 & II & 23 & 364 & 1.95 & 1.76 & 1.18 & 1.19 & 2 & 5 & 1.66 & 1.6 & -0.06 & 95 & 80 & 3 \\
\hline 6 & II & 8 & 363 & 1.94 & 1.98 & 1.16 & 1.18 & 2 & 4 & 1.06 & 0.91 & -0.15 & 95 & 90 & 3 \\
\hline 7 & III & 24 & 356 & 1.32 & 1.31 & 0.66 & 0.72 & 0 & 5 & 0.84 & 0.85 & 0.01 & 92 & 74 & 6 \\
\hline 8 & II & 6 & 468 & 2.01 & 2.15 & 1.18 & 1.31 & 0 & 3 & 1.64 & 1.41 & -0.23 & 98 & 82 & 3 \\
\hline 9 & III & 20 & 342 & 1.49 & 1.37 & 0.84 & 0.87 & 0 & 7 & 1.29 & 1.26 & -0.03 & 95 & 69 & 4 \\
\hline 10 & III & 2 & 424 & 2.28 & 2.26 & 1.01 & 1.03 & 0 & 5 & 1.58 & 1.7 & 0.12 & 95 & 89 & 4 \\
\hline 11 & IV & 29 & 304 & 1.25 & 1.22 & 0.54 & 0.55 & 3 & 7 & 0.54 & 0.67 & 0.13 & 97 & 92 & 7 \\
\hline 12 & I & 4 & 456 & 2.70 & 2.89 & 1.78 & 1.82 & 0 & 3 & 1.67 & 1.85 & 0.18 & 98 & 94 & 0 \\
\hline 13 & II & 9 & 372 & 1.80 & 1.92 & 0.90 & 1.08 & 0 & 4 & 1 & 0.85 & -0.15 & 95 & 83 & 4 \\
\hline 14 & IV & 50 & 410 & 1.20 & 1.11 & 0.50 & 0.51 & 2 & 6 & 0.85 & 0.81 & -0.04 & 96 & 70 & 5 \\
\hline 15 & III & 5 & 432 & 1.39 & 1.47 & 0.90 & 0.96 & 0 & 4 & 1.07 & 1.37 & 0.3 & 94 & 89 & 3 \\
\hline 16 & II & 7 & 360 & 1.90 & 1.81 & 1.03 & 0.98 & 0 & 4 & 1.31 & 1.45 & 0.14 & 97 & 95 & 4 \\
\hline 17 & III & 16 & 342 & 1.63 & 1.51 & 0.89 & 0.83 & 0 & 3 & 0.79 & 1.02 & 0.23 & 94 & 90 & 4 \\
\hline
\end{tabular}

Abbreviations: HRCT: High resolution computed tomography; Pre-: Pre-exercise; Post-: post-exercise; 6MWT: 6 minute walk test. FVC: Forced vital capacity; FEV1: Forced expiratory volume second 1; IC: Inspiratory capacity; BODE score: Body mass index (B), Degree of airflow obstruction (O), Functional dyspnea (D), and Exercise capacity (E).

A

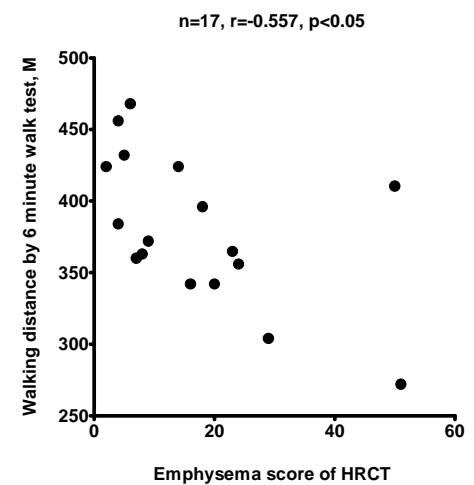

B

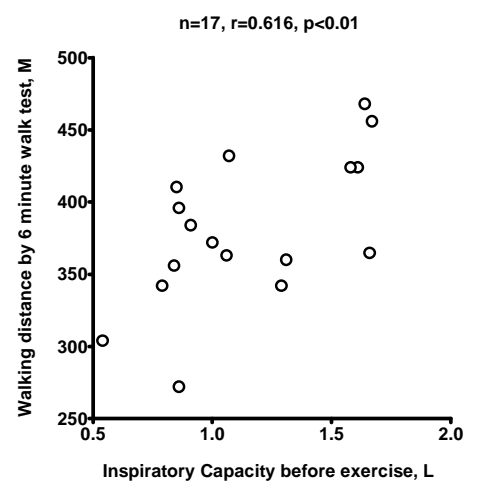

C

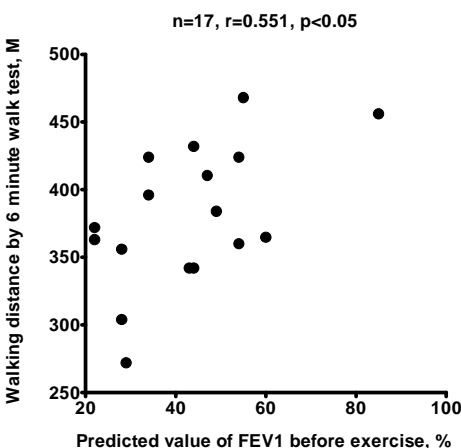

Fig. (1). Walking distance by 6 minute walk test (6MWT) is correlated to the emphysema score of high-resolution computed tomography $(\mathrm{HRCT})(\mathbf{A})$, the inspiratory capacity $(\mathbf{B})$ and \% predicted value of FEV1 (C) before exercise. The number and significance are indicated. 
desaturation (Fig. 2), which also correlates with HRCT emphysema score (Table 3), further demonstrating the possibly impact of anatomical limitations which resulting in $\mathrm{V} / \mathrm{Q}$ mismatch.

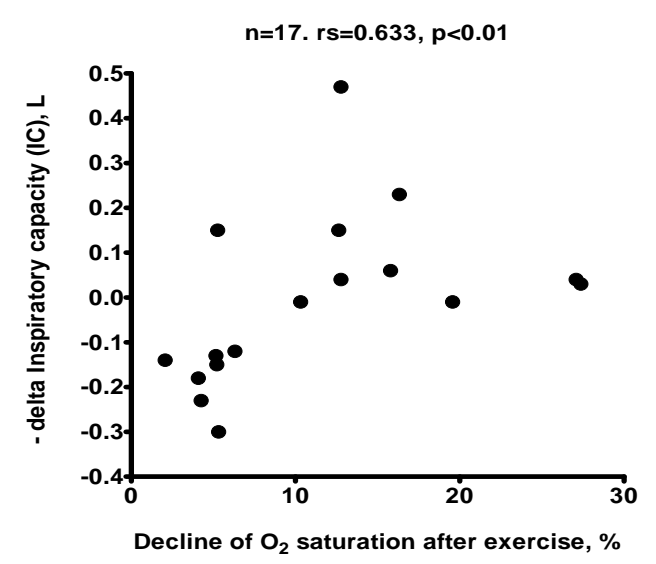

Fig. (2). The change in inspiratory capacity (IC) after exercise directly correlates with the extent of post-exercise oxygen desaturation. The number and significance are indicated.

Compared to 6MWT, CPET adds advantages to 6MWT in prescriptions in pulmonary rehabilitation based on percentage of maximal workload and the anaerobic threshold [17]. The correlations between measures of CPET and HRCT emphysema score show similar trends in pulmonary function, Borg scale, and pre-exercise desaturation (Table 5) as compared to 6MWT. Furthermore, $\mathrm{VO}_{2} \mathrm{Max}$ (Fig. 3A),
Table 3. Correlation Between HRCT Emphysema Score and Lung Function in 6 Minute Walk Test

\begin{tabular}{|l|c|c|c|}
\hline \multicolumn{1}{|c|}{ Emphysema Score Correlated to } & NO. & R & P Value \\
\hline \hline FVC, L (pre-exercise) & 17 & -0.748 & 0.0006 \\
\hline FVC, \% predicted (pre-exercise) & 17 & -0.742 & 0.0006 \\
\hline FVC, L (post-exercise) & 17 & -0.764 & 0.0004 \\
\hline FVC, \% predicted (post-exercise) & 17 & $-0.755-$ & 0.0005 \\
\hline FEV1, L (pre-exercise) & 17 & -0.615 & 0.0086 \\
\hline FEV1, \% predicted (pre-exercise) & 17 & -0.562 & 0.0190 \\
\hline FEV1, L (post-exercise) & 17 & -0.674 & 0.0030 \\
\hline FEV1, \% predicted (post-exercise) & 17 & -0.614 & 0.0087 \\
\hline Inspiratory capacity, L (pre-exercise) & 17 & -0.562 & 0.0189 \\
\hline Inspiratory capacity, L (post-exercise) & 17 & -0.663 & 0.0038 \\
\hline ERV/IC, \% (pre-exercise) & 17 & 0.642 & 0.0054 \\
\hline ERV/IC, \% (post-exercise) & 17 & 0.503 & 0.0396 \\
\hline O2 saturation, \% (post-exercise) & 17 & -0.530 & 0.0287 \\
\hline Borg scale, (post-exercise) & 17 & 0.609 & 0.0094 \\
\hline BODE score & 17 & 0.285 & 0.2674 \\
\hline
\end{tabular}

Abbreviations: FVC: Forced vital capacity; FEV1: Forced expiratory volume second 1; ERV: Expiratory reserve volume; IC: Inspiratory capacity; BODE score: Body mass index (B), Degree of airflow obstruction (O), Functional dyspnea (D), and Exercise capacity (E).
A

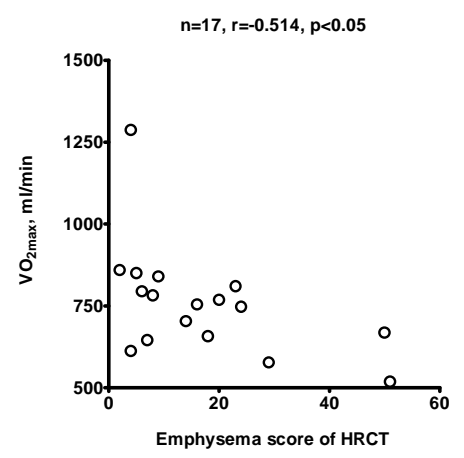

C

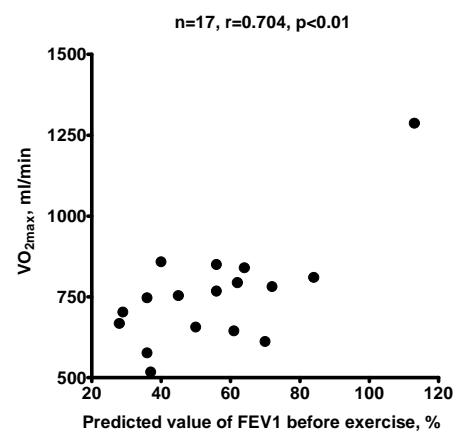

B

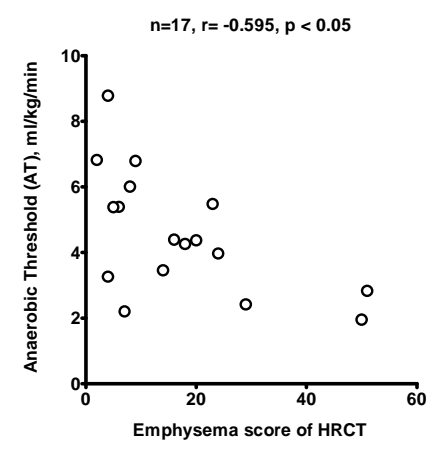

D

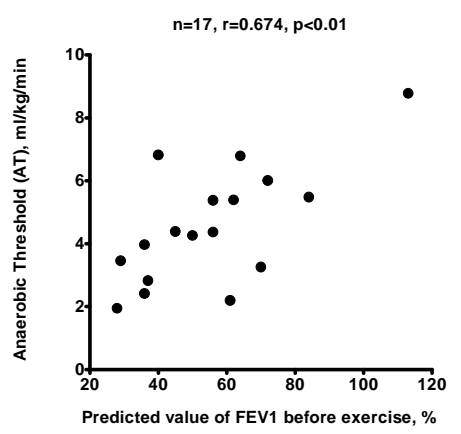

Fig. (3). $\mathrm{VO}_{2} \mathrm{Max}$ (A) and anaerobic threshold (AT) (B) measured by CPET correlate with the emphysema score of high-resolution computed tomography (HRCT) and \% predicted value of FEV1 (C and D). The number and significance are indicated. 
Table 4. Characteristic of HRCT Emphysema Scores and CPET Measurements

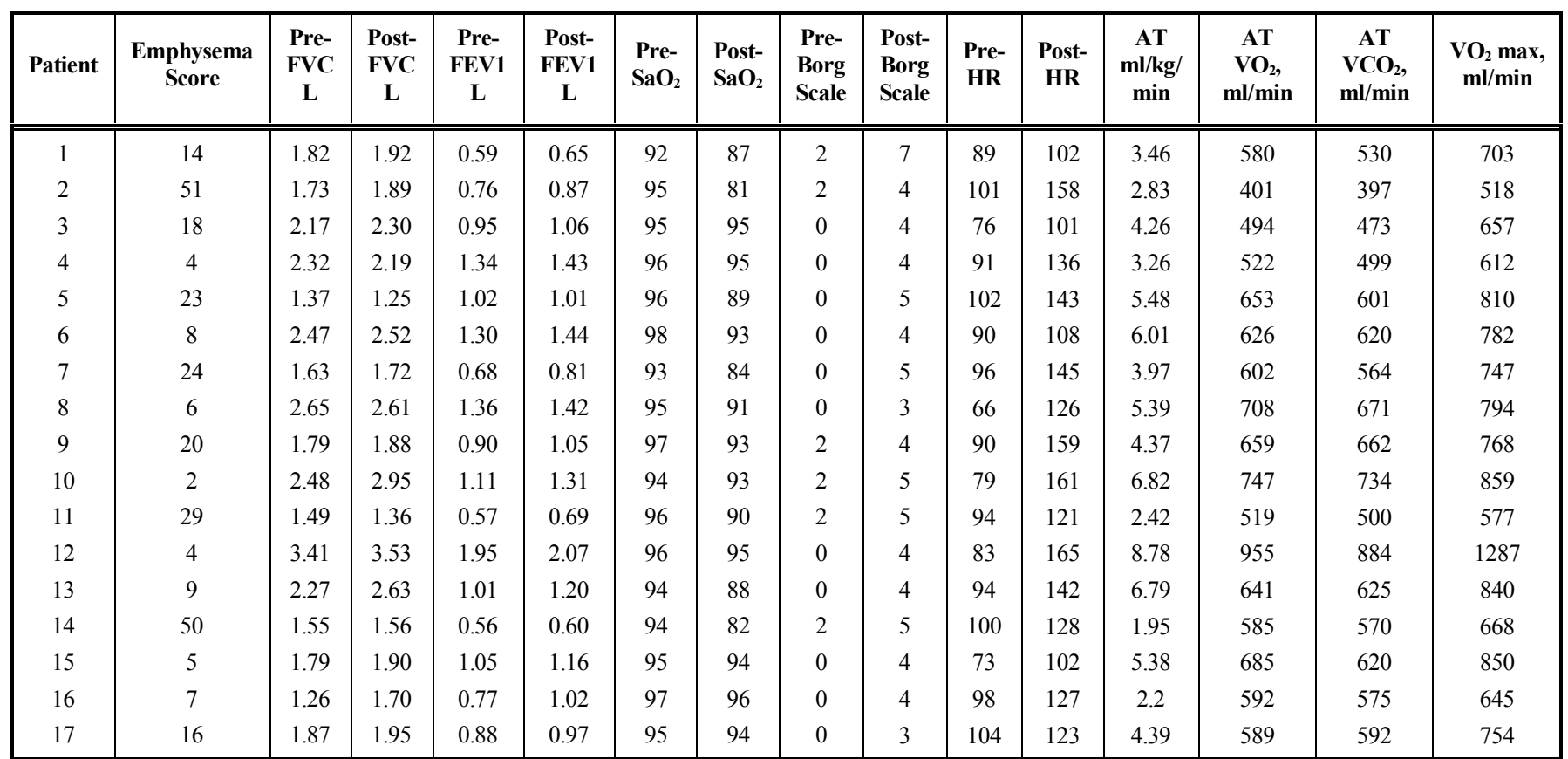

Abbreviations: FVC: Forced vital capacity; FEV1: Forced expiratory volume second 1; ERV: Expiratory reserve volume; IC: Inspiratory capacity; HR: Heart rate; AT: Anaerobic threshold; min: minute.

anaerobic threshold (AT) (Fig. 3B) measured by CPET correlates with the score (Fig. 3). Interestingly, the postexercise desaturation in CPET (Table 5) is positively associated with the score, while 6MWT was not, implying that the effect of exercise intensity may affect the measures over physiologic parameters among two tests.

Table 5. Correlation Between Emphysema Score and Measurement in CPET

\begin{tabular}{|c|c|c|c|}
\hline Emphysema Score Correlated to & NO. & $\mathbf{R}$ & P Value \\
\hline FVC, L (pre-exercise) & 17 & -0.491 & 0.0455 \\
\hline FVC, $\%$ predicted (pre-exercise) & 17 & -0.402 & 0.1096 \\
\hline FVC, L (post-exercise) & 17 & -0.553 & 0.0213 \\
\hline FVC, $\%$ predicted (post-exercise) & 17 & -0.463 & 0.0616 \\
\hline FEV1, L (pre-exercise) & 17 & -0.573 & 0.0162 \\
\hline FVC, $\%$ predicted (pre-exercise) & 17 & -0.484 & 0.0492 \\
\hline FEV1, L (post-exercise) & 17 & -0.627 & 0.0070 \\
\hline FVC, $\%$ predicted (pre-exercise) & 17 & -0.516 & 0.0340 \\
\hline Inspiratory capacity, L (pre-exercise) & 17 & -0.538 & 0.026 \\
\hline Inspiratory capacity, L (post-exercise) & 17 & -0.368 & 0.1612 \\
\hline $\mathrm{AT}, \mathrm{ml} / \mathrm{kg} / \mathrm{min}$ & 17 & -0.595 & 0.0118 \\
\hline $\mathrm{AT}-\mathrm{VO}_{2}, \mathrm{ml} / \mathrm{min}$ & 17 & -0.566 & 0.0179 \\
\hline $\mathrm{AT}-\mathrm{VCO}_{2}, \mathrm{ml} / \mathrm{min}$ & 17 & -0.555 & 0.0207 \\
\hline $\mathrm{VO}_{2} \max , \mathrm{ml} / \mathrm{min}$ & 17 & -0.514 & 0.0350 \\
\hline $\mathrm{O}_{2}$ saturation, $\%$ (post-exercise) & 17 & -0.584 & 0.0138 \\
\hline $\mathrm{HR}, \mathrm{bpm}$, (pre-exercise) & 17 & 0.550 & 0.0223 \\
\hline Borg scale, (pre-exercise) & 17 & 0.541 & 0.025 \\
\hline Borg scale, (post-exercise) & 17 & 0.2051 & 0.4296 \\
\hline
\end{tabular}

Abbreviations: FVC: Forced vital capacity; FEV1: Forced expiratory volume second 1; ERV: Expiratory reserve volume; IC: Inspiratory capacity; HR: Heart rate; AT: Anaerobic threshold; $\mathrm{VO}_{2}$ max: maximal oxygen consumption; min: minute.
The BODE index, which integrates body mass index, airflow limitation (forced expiratory volume in one second), dyspnea and 6-min walk distance, predicts the mortality of COPD, and could be improved by pulmonary rehabilitation $[25,26]$. We found no associations between BODE index and the HRCT emphysema score, which reflects its dynamic variations in nature, or possibly due to limitations of the HRCT score which does not include the degree of airway obstruction and quality of life [27].

To study the morphologic damage in COPD, HRCT is widely used and can help to differentiate between emphysema-predominant and airway-predominant disease or both, which is crucial for determining the appropriate management strategy $[9,28]$. Both qualitative (subjective) and quantitative (objective) methods have been described to assess emphysema by CT scanning [29]. The objective method of measuring the relative lung area occupied by pixels with attenuation coefficients (CT numbers) below a predetermined threshold, is preferable as it can measure the extent of macroscopic emphysema more precisely and in an unbiased way. We have also evaluated visually the size and extent of lung areas affected by emphysema. The correlations between HRCT emphysema visual score and pulmonary function parameters imply that the subjective visual score can be used as an initial evaluation of emphysema severity.

The limitation of this study is the relatively small numbers of patients that includes only 17 patients with COPD. The results may lead to some analytic bias. A larger longitudinal study to include smokers, females, COPD with different severity, and regular follow-up of the patients at fixed intervals may help to identify patient with phenotypes presenting with earlier disease progression and poor prognosis clinically. 


\section{CONCLUSION}

In conclusion, our study supports the notion that COPD associated with higher extent of emphysema on HRCT, is characterized by more severe lung function impairment, more exercise impairment and cardiopulmonary dysfunction. The HRCT emphysema visual scale can be used as an initial parameter for identify patients with high risk for COPD patients with disability.

\section{CONFLICT OF INTEREST}

The authors declare that they have no competing interests.

\section{ACKNOWLEDGEMENT}

This study was supported by Taiwan National Science Council grant, NSC-96-2314-B-182A-130.

\section{REFERENCES}

[1] Global Initiative for Chronic Obstructive Lung Disease. Global strategy for the diagnosis, management and prevention of chronic obstructive pulmonary disease. NHLBI/WHO workshop report 2001. Available at: http://www.goldcopd.org

[2] Barnes PJ. Chronic obstructive pulmonary disease: a growing but neglected global epidemic. PLoS Med 2007; 4: e112.

[3] Eisner MD, Iribarren C, Yelin EH, et al. Pulmonary function and the risk of functional limitation in chronic obstructive pulmonary disease. Am J Epidemiol 2008; 167: 1090-101.

[4] Rennard SI. Chronic obstructive pulmonary disease. Proc Am Thorac Soc 2006; 3: 276-80.

[5] Casanova C, de Torres JP, Aguirre-Jaime A, et al. The progression of chronic obstructive pulmonary disease is heterogeneous: the experience of the BODE cohort. Am J Respir Crit Care Med 2011; 184: 1015-21.

[6] Hasegawa M, Nasuhara Y, Onodera Y, et al. Airflow limitation and airway dimensions in chronic obstructive pulmonary disease. Am J Respir Crit Care Med 2006; 173: 1309-15.

[7] Reilly J. Using computed tomographic scanning to advance understanding of chronic obstructive pulmonary disease. Proc Am Thorac Soc 2006; 3: 450-5.

[8] Omori H, Fujimoto K, Katoh T. Computed-tomography findings of emphysema: correlation with spirometric values. Curr Opin Pulm Med 2008; 14: 110-4.

[9] D'Anna SE, Asnaghi R, Caramori G, et al. High-resolution computed tomography quantitation of emphysema is correlated with eelected lung function values in stable COPD. Respiration 2012; 83: 383-90.

[10] Kohlhäufl M, Brand P, Rock C, et al. Noninvasive diagnosis of emphysema. Am J Respir Crit Care Med 1999; 160: 913-8.

[11] Turner SE, Eastwood PR, Cecins NM, et al. Physiologic responses to incremental and self-paced exercise in COPD: a comparison of three tests. Chest 2004; 126: 766-73.

[12] Han MK, Agusti A, Calverley PM, et al. Chronic obstructive pulmonary disease phenotypes. Am J Respir Crit Care Med 2010; 182: $598-604$
[13] Ross RM, Murthy JN, Wollak ID, et al. The six minute walk test accurately estimates mean peak oxygen uptake. BMC Pulm Med 2010; 10: 31 .

[14] Eaton T, Young P, Milne D, et al. Six-minute walk, maximal exercise tests. Am J Respir Crit Care Med 2005; 171: 1150-7.

[15] Redelmeier DA, Bayoumi AM, Goldstein RS, et al. Interpreting small differences in functional status: the six minute walk test in chronic lung disease patients. Am J Respir Crit Care Med 1997; 155: $1278-82$.

[16] Hiraga T, Maekura R, Okuda Y, et al. Prognostic predictors for survival in patients with COPD using cardiopulmonary exercise testing. Clin Physiol Funct I 2003; 23: 324-31.

[17] Benzo RP, Paramesh S, Patel SJA, et al. Optimal protocol selection for cardiopulmonary exercise testing in severe COPD. Chest 2007; 132: $1500-5$

[18] Miniati M, Filippi E, Falaschi F, et al. Radiologic evaluation of emphysema in patients with chronic obstructive pulmonary disease. Chest radiography versus high resolution computed tomography. Am J Respir Crit Care Med 1995; 151: 1359-67.

[19] Park KJ, Bergin CJ, Clausen JL. Quantitation of emphysema with three-dimensional CT densitometry: comparison with two dimensional analysis, visual emphysema scores and pulmonary function tests results. Radiology 1999; 211: 541- 7 .

[20] Sakai F, Gamsu G, Im JG, et al. Pulmonary function abnormalities in patients with CT-determined emphysema. J Comput Assist Tomogr 1987; 11: 963-8.

[21] Barnes PJ. Chronic obstructive plmonary disease: effects beyond the lungs. PLoS Med 2010; 7: e1000220.

[22] Barnes PJ, Celli BR. Systemic manifestations and comorbidities of COPD. Eur Respir J 2009; 33: 1165-85.

[23] Strijbos JH, Postma DS, van Altena R, et al. A comparison between an outpatient hospital-based pulmonary rehabilitation program and a home-care pulmonary rehabilitation program in patients With COPD: A follow-up of 18 months. Chest 1996; 109: 366-72.

[24] van Stel HF, Bogaard JM, Rijssenbeek-Nouwens LH, et al. Multivariable assessment of the 6-min walking test in patients with chronic obstructive pulmonary disease. Am J Respir Crit Care Med 2001; 163: 1567-71.

[25] Cote CG, Celli BR. Pulmonary rehabilitation and the BODE index in COPD. Eur Respir J 2005; 26: 630-6.

[26] Martinez FJ, Han MK, Andrei AC, et al. National Emphysema Treatment Trial Research Group: Longitudinal change in the BODE index predicts mortality in severe emphysema. Am J Respir Crit Care Med 2008; 178: 491-9.

[27] Martinez $\mathrm{CH}$, Chen Y-H, Westgate PM, et al. COPD Gene Investigators: Relationship between quantitative $\mathrm{CT}$ metrics and health status and BODE in chronic obstructive pulmonary disease. Thorax 2012; 67: 399-406

[28] Matsuoka S, Yamashiro T, Washko GR, et al. Quantitative CT assessment of chronic obstructive pulmonary disease. Radiographics 2010; 30: 55-66.

[29] Baldi S, Miniati M, Bellina CR, et al. Relationship between extent of pulmonary emphysema by high-resolution computed tomography and lung elastic recoil in patients with chronic obstructive pulmonary disease. Am J Respir Crit Care Med 2001; 164:585-9. 